Vol 12, Issue 12, 2019

Online - 2455-3891

Print - 0974-2441

$\underline{\text { Research Article }}$

\title{
QUALITY OF LIFE ASSESSMENT IN THE HEART FAILURE PATIENTS TAKING STANDARD MEDICAL CARE IN TEACHING HOSPITAL
}

\begin{abstract}
PRIYANKA SHARMA ${ }^{1}$, MD SAYEED AKHTAR ${ }^{2}$, FAUZIA TABASSUM ${ }^{3}$, NIMISHA TANDON ${ }^{1}$, ANSHU NANDA ${ }^{1 *}$
${ }^{1}$ Department of Clinical Research, School of Allied Health Sciences, Sharda University, Greater Noida, Uttar Pradesh, India. ${ }^{2}$ Department of Clinical Pharmacy, College of Pharmacy, King Khalid University, Asir, Abha, Saudi Arabia. ${ }^{3}$ Department of Pharmacology, All India Institute of Medical Sciences, Patna, Bihar, India. Email: anshu.nanda@rediffmail.com
\end{abstract}

Received: 19 August 2019, Revised and Accepted: 21 October 2019

ABSTRACT

Objective: This study was aimed to assess the quality of life (QoL) of the subjects having congestive heart failure (HF) under different domains of life, such as physical, psychological, and social domains, and they started taking the standard care treatment.

Methods: The questionnaire-based prospective study was designed to assess the effects of the HF in different domains of life such as social, psychological, physical, or mental. After getting consent from the subjects, health questionnaire was provided to a total of 60 subjects.

Results: We found drastic improvements in $24 \%$ of total HF cases in terms of physical debility, whereas only $15 \%$ patients reported none of the complications during taking standard care therapy. Total $32.5 \%$ patients aware of the treatment took and to whom contact in an emergency. Psychological disturbances and life satisfaction were observed in $16.66 \%$ and $33.33 \%$ cases suffering from HF. Patient compliance means personal life, as well as medication adherence, was observed in only $53.33 \%$.

Conclusions: The results obtained from the responses given by the patients in the health questionnaires demonstrated that the HF patients' needs awareness regarding the therapy precautions that improving the QoL of patients.

Keywords: Heart failure, Quality of life, Compliance, Awareness.

(c) 2019 The Authors. Published by Innovare Academic Sciences Pvt Ltd. This is an open access article under the CC BY license (http://creativecommons. org/licenses/by/4. 0/) DOI: http://dx.doi.org/10.22159/ajpcr.2019.v12i12.35396

\section{INTRODUCTION}

Patients' quality of life (QoL) has equal importance similar to survival in patients suffering from chronic and progressive illness [1]. Every year, almost 17.7 million people died due to cardiovascular diseases (CVDs) that constitute around $31 \%$ of all global deaths [2]. Heart failure (HF) leads to structural and functional irregularities in cardiac muscles that results in reduced cardiac output and raised intra-cardiac pressures either at rest or even during stress [3]. QoL severely affected and progresses over the time passes as the heart has to compensate for the abnormalities caused by various heart disorders [4]. Coronary artery disease and uncontrolled hypertension are one of the major causative factors of HF in cardiac cases, whereas sedentary lifestyle, alcohol and drug abuse play a major risk factor in developing HF [4].

In the last decade, various studies have demonstrated a widespread application of evidence-based medicine and devices that resulted in significant improvements in survival of congestive HF (CHF) patients [5]. Although improving survival remains clinically important and many patients with advanced $\mathrm{HF}$, even giving equal or more importance to QoL in comparison to the life expectancy. QoL in patients with CHF causes more severe impairment of both physical and psychosocial functioning [6]. Thus, maintaining a high QoL is as vital as survival for the most CVDs patients suffering from chronic HF [7]. It has been reported that QoL of the HF patients is severely impaired in comparison to patients with other major chronic illnesses [8-11]. QoL of the patients imitates the impact of a diseased status in different prospects of life aspect and then outcome of treatment on patients' daily lives [12-14]. Patients with HF sense different physical and emotional indications such as edema, dyspnea, fatigue, difficulty in sleeping, chest pain, and depression $[15,16]$. These associated difficulties limit the daily physical as well as social activities of the patient that lead to deprived QoL [17-19]. Physical and social limitations related poor QoL have high rates of hospitalization and mortality [20,21]. Therefore, QoL should be assessed definitely to establish its impact on daily life in $\mathrm{HF}$ patients. The major aim of the HF treatment in clinical practice is to improve the QoL of the patients [22]. In spite the increased prevalence of HF cases, only limited studies were conducted looking impact of $\mathrm{CHF}$ on QoL. The QoL assessment, especially in elderly patient is the need of hour for improving their positive mental health status in HF cases. This study was aimed to explore the outcomes of clinical, social, and psychological factors on QoL cases suffering from CHF.

\section{METHODS}

Patients were informed regarding the study, and consent was also taken for their participation. The questions were answered by the patients in a way to compare their health status from the time they had been diagnosed to have HF, and then they started taking the standard care therapy and their health status as of the day filling the questionnaire.

\section{Setting}

A total sample of 60 patients with confirmed HF who lived in the metropolitan city were participated in this qualitative study.

\section{Aim of the study}

The aim of the study was to assess the QoL of the subjects having CHF under different domains of life such as physical, mental, and social from the time they started taking the standard care treatment as the medical management strategy.

\section{Primary objective}

The primary objective of the study was the assessment of the QoL in different domains of life of HF patients. Furthermore, the patients were observed for the occurrence of endpoints such as re-hospitalizations, the occurrence of any other cardiac disorder. 
Study type

An observational prospective study was designed to measure the QoL in HF patients.

\section{Inclusion criteria}

The following criteria were included in the study:

- Age of above 18 years

- Education (patient must be able to read, understand, and sign the informed consent form and could provide the information in the health questionnaire)

- Patients diagnosed with confirmed HF

- Patients taking standard care of treatment.

\section{Exclusion criteria}

The following criteria were excluded from the study:

- Patients suffering from any of the chronic comorbidities such as chronic kidney failure and chronic obstructive pulmonary disease

- Patients suffering from mental disorders

- Illiterate subjects or the subjects who are not able to give informed consent

- Chronic alcohol consumers as well as smokers

- Any life-threatening disorder.

\section{Conduct of the study}

The basis for the conduct of this study was the assessment of QoL using the health-related questionnaires duly filled by the participants. Participants were provided with the informed consent forms and they were informed about the survey being conducted for the purpose of completing the thesis work that will also benefit our society. The questionnaire was provided to the subjects, explained and then consent from the subjects was obtained. We selected $60 \mathrm{HF}$ patients on the basis of the mentioned inclusion and the exclusion criteria. Subjects filled up the questionnaires on the basis of their health status as compared to their health status at the time they were diagnosed with having $\mathrm{HF}$, and they started taking the standard care therapy. The statistical analysis of the data obtained from questionnaires was performed and then interpretations of the effects of HF on the QoL in participants were performed.

Telephonic follow-up was performed for the subjects after 3 months so as to determine the occurrence of any endpoint (re-hospitalization, death, or any other cardiac disorder).

\section{Statistical analysis}

Statistical analyses were conducted using SPSS version 12 for Windows 10. Data were pictorially displayed using the histogram. Data are presented as frequencies and percentages depending on the level of measurement.

\section{RESULTS}

The analysis was done in the same order; the questions are there in the questionnaire.

\section{Physical status (benefits and complications) in HF patients after} standard therapy

In the $200 \mathrm{~m}$ walk on the ground, we observed that among 60 patients, $18(30 \%)$ patients were observed to be difficulty in walking, and $20(33.33 \%)$ patients had moderate difficulty, whereas 22 (36.66\%) patients were reported not to have any difficulty in walking. To perform the usual household activities, 16 (26.66\%) HF patients were reported to have difficulty in performing usual household activities and 28 (46.66\%) of them reported moderate difficulty, whereas 16 (26.66\%) patients had no problem at all in doing the activities. After starting the standard care therapy, improvement in the symptoms of heart failure such as shortness of breath, tiredness, and ankle swelling was the major concern in HF cases. Out of 60 patients, 16 (26.66\%) responded better improvements in symptoms, whereas $34(56.66 \%)$ reported a slight improvement in symptoms whereas the condition became worsened in $10(16.66 \%)$ patients. As per the frequencies of the occurrence of swelling in feet, ankles or legs were concerned after taking standard care therapy. We observed $19(31.66 \%)$ patients had swelling in ankles every morning, $21(35 \%)$ reported the same $1-2$ times a week, whereas $21(35 \%)$ patients suffered from the same more than 3 times a week. Similarly, in climbing up the stairs we observed that among $60 \mathrm{HF}$ subjects, $26(43.33 \%)$ and $24(40 \%)$ cases had difficulty and moderate difficulty in climbing, respectively, while $10(16.66 \%)$ cases reported to not have any problem in climbing the stairs. A total $21(35 \%)$ patients reported to have tiredness that extremely limited the desired activities and made it troublesome, whereas $30(50 \%) \mathrm{HF}$ patients reported moderate difficulty and $9(15 \%)$ out of them reported no any problem at all (Table 1). A total of $15(25 \%)$ patients among the 60 patients experienced shortness of breath in sleeping and needs the chair or keeping at least three pillows to keep yourself upright every night, whereas 27 (45\%) of them suffer from the same 2-3 times a week and $18(30 \%)$ patients suffer from the difficulty less than once a week.

\section{Awareness regarding the disease}

Only $20(33.33 \%)$ patients reported that they were well aware of the precautions to follow to avoid worsening the HF symptoms (like a low salt diet and regular monitoring body weight), whereas 31 (51.66\%) patients reported somewhat aware and $9(15 \%)$ were not at all aware of the precautions. Among 60 patients, 19 (31.66\%) patients were well aware of the symptoms that can increase HF cases and whom to contact in that situation, whereas $29(48.33 \%)$ and $12(20 \%)$ patients were somewhat aware and not aware of this, respectively (Fig. 1).

\section{Life satisfaction and psychological disturbance}

Only $15(25 \%)$ patients were reported that HF very less affected the life and feel regarding the limitation imposed by HF in the enjoyment of your life against those 19 (31.66\%) patients who reported to be severely affected the life, whereas $26(43.33 \%)$ reported moderately affected regarding the limitation imposed by HF (Fig. 2).

As per the feeling depressed because of the HF symptoms, 10 (16.66\%) out of the 60 patients reported that they rarely feel anxious or depressed. About $22(36.66 \%)$ patients reported that they often feel depressed, whereas $28(46.66 \%)$ patients reported that they often remain depressed due to HF symptoms (Fig. 2).

\section{Patients' compliance}

A total of $20(33.33 \%)$ patients reported that the health status was satisfactorily improved post standard care of treatment against $7(11.66 \%)$ patients not at all improved, whereas 33 (11.66\%) reported that health status was moderately improved post standard care. Only $15(25 \%)$ patients were reported that standard care therapy severely limited their hobbies, whereas $31(51.66 \%)$ and $14(23.33 \%)$ patients of them reported being moderately and slightly limited their hobbies, respectively. For visiting family or friends, almost 14 (23.44\%) patients reported that they feel severely limited in visiting their family and friends, $28(46.66 \%)$ of them feel it has moderately affected, and 18 (30\%) patients feel slightly affected. In terms of comfortable taking the medications prescribed by the investigator for lifelong, only

Table 1: Physical health status (benefits/complications) after taking standard HF therapy

\begin{tabular}{|c|c|c|c|}
\hline Indices $(n=60)$ & Major (\%) & Moderate (\%) & Minor (\%) \\
\hline Diffic & 18 & $20(33.33)$ & $22(36.66)$ \\
\hline $\begin{array}{l}\text { Difficulty in usual } \\
\text { household activities }\end{array}$ & ) & & $16(26.66)$ \\
\hline $\begin{array}{l}\text { Improvements in HF } \\
\text { symptoms }\end{array}$ & $16(26.66)$ & $34(56.66)$ & $10(16.66)$ \\
\hline $\begin{array}{l}\text { Occurrence of HF } \\
\text { symptoms }\end{array}$ & 19 (31.66) & $20(33.33)$ & $21(35)$ \\
\hline $\begin{array}{l}\text { Difficulty in climbing } \\
\text { stairs }\end{array}$ & $26(43.33)$ & $24(40)$ & $10(16.66)$ \\
\hline Tiredness & $21(35)$ & $30(50)$ & $9(15)$ \\
\hline
\end{tabular}




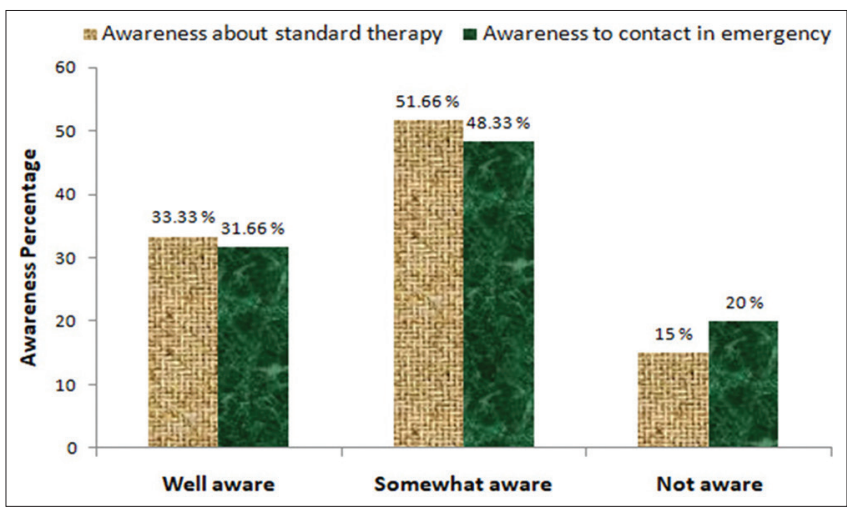

Fig. 1: Awareness about treatment during standard therapy in heart failure $n=60$

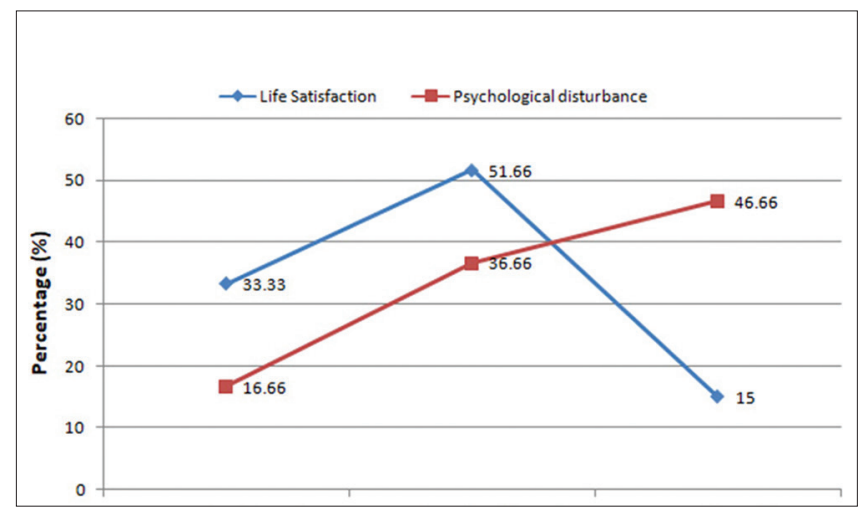

Fig. 2: Life satisfaction and psychological disturbances during standard therapy in heart failure $n=60$

$15(25 \%)$ patients reported to be very much comfortable in taking the medications prescribed, $31(51.66 \%)$ patients were moderately comfortable, whereas $14(23.33 \%)$ patients were not comfortable at all (Fig. 3)

\section{Assessment of the telephonic follow-up}

At the end of 3 months from the date of signing the informed consent, a telephonic follow-up for the patients was performed to determine if they had experienced any kind of event such as re-hospitalization or re-occurrence of any cardiac morbidities and their compliance to the standard care therapy. We observed that $54(90 \%)$ patients out of 60 were doing well and experienced improvement in the symptomatic effects of HF. Along with this, 56 (93.33\%) patients out of 60 patients have become compliant to the standard care therapy and they were continuing taking the same medications as prescribed. It was also observed that $3(5 \%)$ patients got hospitalized due to the development of comorbidities due to effects on renal and the pulmonary system and they were referred to the specialists for further examinations. We also not observed any worsening in the functional class of $\mathrm{HF}$, as there was no symptomatic deterioration occurred in the patients (Fig. 4).

\section{DISCUSSION}

According to the World Health Organization health is a state of complete physical, mental, and social well-being not merely the absence of disease. Similarly, QoL of every individual patients is perceived differently as per their culture and values [23]. The therapeutic intervention was aimed to improve patient care in CHF cases and prognosis as well as maximizing daily life activities [24]. Our aim of the present study was to observe the relationship between recommended standard treatment, QoL, and the severity of the CHF disease as earlier reported [8]. Among all the prevalence, symptoms, sleeping difficulty was ranked the highest as QoL trouble. Recently, a QoL study reported that in HF cases the sleep

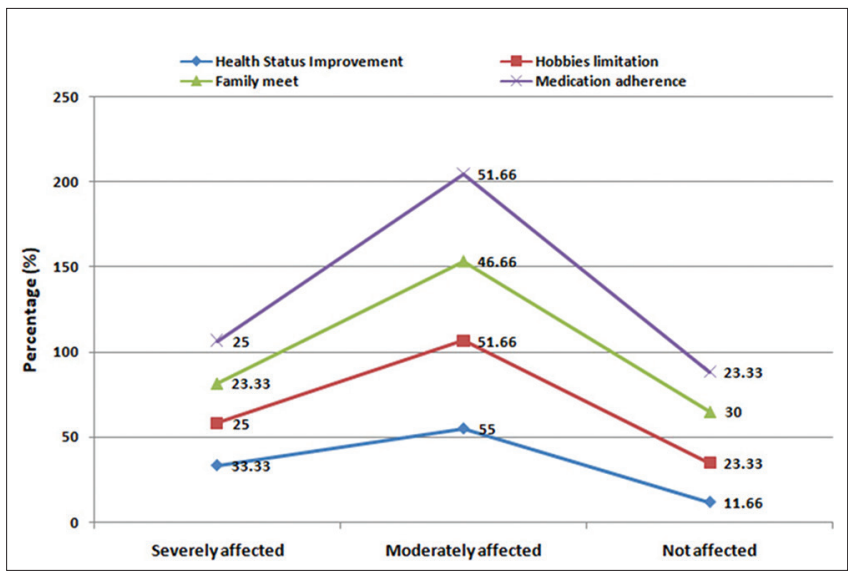

Fig. 3: Health status and social life and medication adherence during standard therapy in heart failure $n=60$

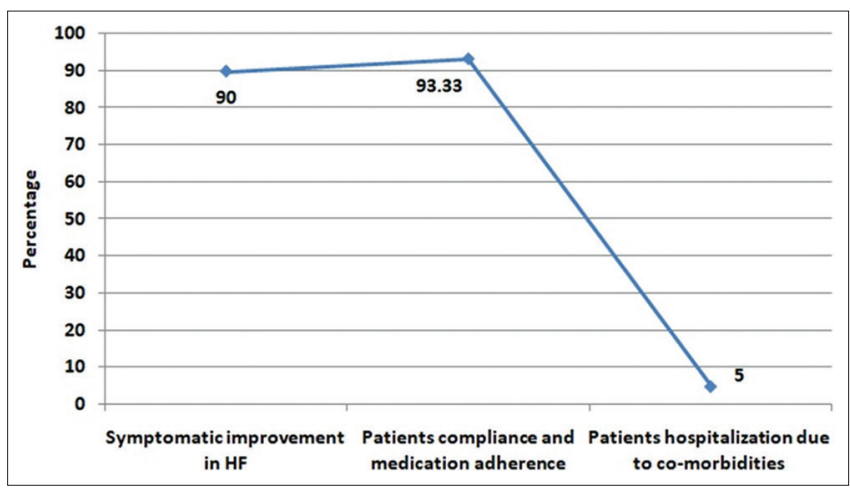

Fig. 4: Patient overall health status during standard therapy in heart failure $n=60$

disorder initiates number of debility symptoms, mainly diminished alertness, tiredness, and anger $[25,26]$. More than $80 \%$ of HF cases have been reported to suffer from physical limitations such as irregular breathing, peripheral edema, anxiety, and these symptoms troubles and degrades the QoL [27]. These deteriorating symptoms become major factor for the re-hospitalization of HF patients [28].

Another factor affecting, QoL was future time anxiety and depression, and also with the problem in concentrating on work was major challenges and greatly affects in performing daily activities. Consistently, we observed that large number of patients with $\mathrm{HF}$ was suffering from depression, as similar findings were earlier reported [29-31]. These psychological disturbances cause negative impact on QoL in HF patients and have strong correlation to adhere, morbidity, and mortality [32,33].

Implementations of awareness program in the HF patients about any intervention in disease treatment have greater impact in QoL. For increasing patient adherence, implementation of awareness programs has been always recommended and reported to have a major role in decreased re-hospitalization and even mortality $[34,35]$.

The telephonic follow-up interprets that in a period of 3 months the patient has become regular in taking the medications regularly, and fewer hospitalizations occur. Among them, three cases were readmitted because the patients developed some renal or pulmonary comorbidity, but there was no mortality.

\section{CONCLUSIONS}

We concluded that QoL explains the outcome of both illnesses and its treatment perceived by the HF patient. These outcomes are a key in an important decision-making measure in all physical, mental, and social 
domains to achieve better patient compliance. The awareness among the patients regarding the precautions taken and consideration about symptoms that may cause aggravation of the disease severity has also added to improving the QoL of the HF patients. The limitations of the study are the small sample size and lack of comparison with the control group.

\section{ACKNOWLEDGMENTS}

The authors are like to express his gratitude to King Khalid University, Abha, Saudi Arabia, for providing administrative and technical support for providing required facilities.

\section{AUTHOR'S CONTRIBUTIONS}

All the authors contributed substantially to the research work.

\section{CONFLICTS OF INTEREST}

The authors declare that they no conflicts of interest concerning this research article.

\section{REFERENCES}

1. Lewis EF, Johnson PA, Johnson W, Collins C, Griffin L, Stevenson LW. Preferences for quality of life or survival expressed by patients with heart failure. J Heart Lung Transplant 2001;20:1016-24

2. Available from: http://www.who.int/en/news-room/fact-sheets/detail/ cardiovascular-diseases-(cvds). [Last accessed on 2019 Aug 19].

3. Ponikowski P, Voors AA, Anker SD, Bueno H, Cleland JG, Coats AJ, et al. 2016 ESC Guidelines for the diagnosis and treatment of acute and chronic heart failure: The task force for the diagnosis and treatment of acute and chronic heart failure of the European society of cardiology (ESC)Developed with the special contribution of the heart failure association (HFA) of the ESC. Eur Heart J 2016;37:2129-200.

4. Buttar HS, Li T, Ravi N. Prevention of cardiovascular diseases: Role of exercise, dietary interventions, obesity and smoking cessation. Exp Clin Cardiol 2005;10:229-49.

5. MacIntyre K, Capewell S, Stewart S, Chalmers JW, Boyd J, Finlayson A, et al. Evidence of improving prognosis in heart failure: Trends in case fatality in 66547 patients hospitalized between 1986 and 1995. Circulation 2000;102:1126-31.

6. Heo S, Lennie TA, Okoli C, Moser DK. Quality of life in patients with heart failure: Ask the patients. Heart Lung 2009;38:100-8.

7. Riedinger MS, Dracup KA, Brecht ML. Quality of life in women with heart failure, normative groups, and patients with other chronic conditions. Am J Crit Care 2002;11:211-9.

8. Juenger J, Schellberg D, Kraemer S, Haunstetter A, Zugck C, Herzog W, et al. Health related quality of life in patients with congestive heart failure: Comparison with other chronic diseases and relation to functional variables. Heart 2002;87:235-41.

9. van Jaarsveld CH, Sanderman R, Miedema I, Ranchor AV, Kempen GI. Changes in health-related quality of life in older patients with acute myocardial infarction or congestive heart failure: A prospective study. J Am Geriatr Soc 2001;49:1052-8.

10. Dixon T, Lim LL, Oldridge NB. The MacNew heart disease healthrelated quality of life instrument: Reference data for users. Qual Life Res 2002;11:173-83.

11. Riedinger MS, Dracup KA, Brecht ML, SOLVD Investigatos Studies of Left Ventricular Dysfunction. Quality of life in women with heart failure, normative groups, and patients with other chronic conditions. Am J Crit Care 2002;11:211-9.

12. Grady KL, Jalowiec A, White-Williams C, Pifarre R, Kirklin JK, Bourge RC, et al. Predictors of quality of life in patients with advanced heart failure awaiting transplantation. J Heart Lung Transplant $1995 ; 14: 2-10$.

13. Westlake C, Dracup K, Creaser J, Livingston N, Heywood JT, Huiskes BL, et al. Correlates of health-related quality of life in patients with heart failure. Heart Lung 2002;31:85-93.

14. Dracup K, Walden JA, Stevenson LW, Brecht ML. Quality of life in patients with advanced heart failure. J Heart Lung Transplant
1992;11:273-9.

15. Nordgren L, Sörensen S. Symptoms experienced in the last six months of life in patients with end-stage heart failure. Eur J Cardiovasc Nurs 2003;2:213-7.

16. Zambroski CH, Moser DK, Bhat G, Ziegler C. Impact of symptom prevalence and symptom burden on quality of life in patients with heart failure. Eur J Cardiovasc Nurs 2005;4:198-206.

17. Coelho R, Ramos S, Prata J, Bettencourt P, Ferreira A, CerqueiraGomes M. Heart failure and health related quality of life. Clin Pract Epidemiol Ment Health 2005;1:19.

18. Boyd KJ, Murray SA, Kendall M, Worth A, Frederick Benton T, Clausen $\mathrm{H}$. Living with advanced heart failure: A prospective, community based study of patients and their carers. Eur J Heart Fail 2004;6:585-91.

19. Rector TS, Anand IS, Cohn JN. Relationships between clinical assessments and patients' perceptions of the effects of heart failure on their quality of life. J Card Fail 2006;12:87-92.

20. Alla F, Briançon S, Guillemin F, Juillière Y, Mertès PM, Villemot JP, et al. Self-rating of quality of life provides additional prognostic information in heart failure. Insights into the EPICAL study. Eur J Heart Fail 2002;4:337-43.

21. Konstam V, Salem D, Pouleur H, Kostis J, Gorkin L, Shumaker S, et al. Baseline quality of life as a predictor of mortality and hospitalization in 5,025 patients with congestive heart failure. SOLVD investigations. Studies of left ventricular dysfunction investigators. Am J Cardiol 1996;78:890-5.

22. Davis RC, Hobbs RF, Kenkre JE, Roalfe AK, McLeod S, Hare R, et al. Quality of life in heart failure and others conditions. JACC 1999;33:211A

23. Available from: http://www.who.int/healthinfo/survey/whoqolqualityoflife/en. [Last Accessed on 2019 Aug 19].

24. Bullinger M. Health related quality of life and subjective health. Overview of the status of research for new evaluation criteria in medicine. Psychother Psychosom Med Psychol 1997;47:76-91.

25. Broström A, Strömberg A, Dahlström U, Fridlund B. Patients with congestive heart failure and their conceptions of their sleep situation. J Adv Nurs 2001;34:520-9.

26. Murberg TA, Bru E, Svebak S, Tveterås R, Aarsland T. Depressed mood and subjective health symptoms as predictors of mortality in patients with congestive heart failure: A two-years follow-up study. Int J Psychiatry Med 1999;29:311-26.

27. Heo S, Moser DK, Lennie TA, Chung ML. Gender differences in the effects of physical and emotional symptoms on health-related quality of life in patients with heart failure. Circulation 2005;111:E-59.

28. Parshall MB, Welsh JD, Brockopp DY, Heiser RM, Schooler MP, Cassidy KB. Dyspnea duration, distress, and intensity in emergency department visits for heart failure. Heart Lung 2001;30:47-56.

29. Friedman MM. Older adults' symptoms and their duration before hospitalization for heart failure. Heart Lung 1997;26:169-76.

30. Havranek EP, Ware MG, Lowes BD. Prevalence of depression in congestive heart failure. Am J Cardiol 1999;84:348-50, A9.

31. Juenger J, Kraemer S, Schellberg D, Habich A, Zugck C, Haass M, et al. Quality of Life, anxiety and depression dependent on NYHAclass in patients with chronic heart failure [abstract]. Psychosom Med 1998;60:106-7.

32. Jiang W, Alexander J, Christopher E, Kuchibhatla M, Gaulden LH, Cuffe MS, et al. Relationship of depression to increased risk of mortality and rehospitalization in patients with congestive heart failure. Arch Intern Med 2001;161:1849-56.

33. Noviyani R, Indrayathi PA, Budiana IN, Suwiyoga K, Tunas K. Assessment of life quality in patients with stage IIB-IIIB squamous cell cervical cancer receiving paclitaxel cisplatin chemotherapy regimen by eortc QLQ-C30 questionnaire in sanglah hospital Denpasar. Int J Pharm Pharm Sci 2017:9:222-6.

34. Ruppar TM, Cooper PS, Mehr DR, Delgado JM, Dunbar-Jacob JM. Medication adherence interventions improve heart failure mortality and readmission rates: Systematic review and meta-analysis of controlled trials. J Am Heart Assoc 2016;5:e002606.

35. Mohammed Al-Z AA, AL-Amrani MA, Alakhali KM, Aljaber N. Evaluation of medication compliance in patients with congestive heart failure in Yemen. Int J Pharm Pharm Sci 2019;11:93-7. 